Richards-Schuster, K. (2012). Empowering the voice of youth: The role of youth advisory councils in grant making focused on youth. In R. VeLure Roholt \& M. L. Baizerman (Eds.), Evaluation advisory groups. New Directions for Evaluation, 136, 87-100.

\title{
Empowering the Voice of Youth: The Role of Youth Advisory Councils in Grant Making Focused on Youth
}

\author{
Katie Richards-Schuster
}

\begin{abstract}
This article will focus on the potential role for youth evaluation advisory groups within youth grant-making organizations and networks. The main elements to be discussed include the formation of the network, the training program elements, some specific examples of efforts by young people to create and strengthen evaluation within their YACs (youth advisory councils), and the lessons learned. (C)iley Periodicals, Inc., and the American Evaluation Association.
\end{abstract}

The construction of youth voice and youth participation in advicegiving roles remains an important issue for discussion. Despite increasing efforts to engage young people in this way and increasing scholarship on the topic, youth participation is still marginalized in society. In general, American society, through its policies and practices, tends to focus on the construction of youth as vulnerable and at risk at best, and as problems at worst (Finn, 2001; Finn \& Checkoway, 1998). This construction has lead to a resistance to the idea of including young people as policy,

Special thanks is given to Cheryl Elliott, president and CEO of the Ann Arbor Area Community Foundation, for her feedback, comments, and support of this case study.

New Directions for Evaluation, no. 136, Winter 2012 (C) Wiley Periodicals, Inc., and the American Evaluation Association. Published online in Wiley Online Library (wileyonlinelibrary.com) • DOI: 10.1002/ev.20036 
program, and evaluator advisors, especially for the most marginalized and disconnected youth. As a result, youth programs tend to focus on protecting or fixing young people's problems rather than on the assets and contributions that young people can make to society (Camino \& Zeldin, 2002; Checkoway \& Richards-Schuster, 2002, 2006; Finn, 2001; Finn \& Checkoway, 1998; Zeldin et al., 2001).

In contrast is a perspective that views young people as competent citizens with a right and responsibility to engage in their communities. This perspective makes the assumption that youth participation provides a legitimate source of information and ideas for making policy, planning, and program decisions, for young people have everyday experiences that position them to "provide a different lens" (Noguera, 2003, p. 135) and "raise issues ... that might not have otherwise been on the radar of adults" (Endo, 2002 , p. 3). This perspective assumes that democracy is strengthened through the participation and active engagement of all people-including young people-in the process (Camino \& Zeldin, 2002; Checkoway, 1998; Checkoway et al., 2003; Checkoway, Allison, \& Montoya, 2005; Checkoway \& Gutierrez, 2006; Checkoway \& Richards-Schuster, 2002, 2006).

This perspective, albeit growing in practice and scholarship, still challenges dominant-society paradigms and creates the potential for the shifting of power dynamics within organizations and communities. As such, efforts to engage young people in these ways are still generally seen as exceptions rather than the norm in communities, and many adults are still resistant to the idea and practice of including young people as policy, program, and evaluator advisors.

Youth participation in philanthropy represents a model for exploring questions about youth voice in advice-giving roles. Over the last 20 years, there have been a number of efforts by large foundations, community foundations, and organizations to engage young people in having a voice in the process of grant decisions (Falk \& Nissan, 2007; Tice, 2004, Youth Leadership Institute, 2001).

Youth participation of this type includes efforts by youth grant makers affiliated with community foundations to assess community needs for grant-making priorities, establish procedures for grantees to evaluate their activities and outcomes, and evaluate the effectiveness of themselves and their grant-making.

Efforts to engage young people in philanthropy have at their core the concept that youth participation is good for grant making and that their voice contributes to perspective on youth needs, provides information for program planning and decision making, and improves the overall community. In addition, youth participation of this type strengthens social development of young people and prepares them for active participation in a democratic society (Falk \& Nissan, 2007; Checkoway et al., 2003; Tice, 2004).

Because of their uniqueness as a model for youth participation that is growing and thriving, these types of youth participation provide a case for 
examining best practices around how youth advisory boards function, how they can be sustained, and how they can empower youth voice within communities.

This chapter explores these questions through the lens of a statewide youth grant-making network, with focus given to a specific example of a youth advisory council within a community foundation. The data from this case study draw from organization documentation and the author's experience as a staff advisor to the Ann Arbor Area Community Foundation Youth Council from 2002-2005.

\section{Background and History}

In the late 1980s, the W. K. Kellogg Foundation launched a challenge grant program as a commitment to growing community foundations and strengthening youth participation. The challenge grant sought to grow existing or create new community foundation endowments through a 2:1 match; for every 2 million dollars a community foundation could raise for its endowment, the W. K. Kellogg Foundation would provide 1 million dollars to each foundation to fund a youth endowment that would be advised by a youth committee. In this step, the W. K. Kellogg Foundation provided a permanent vehicle for youth participation within community foundations across the state of Michigan. Known as Youth Advisory Committees (YACs), these committees created roles for young people to have an active voice in grant making in their communities. Although YACs were structured in various forms based on the individual community foundations, all YACs were expected to (a) conduct needs assessments every 3 years to identify needs and determine grant priorities, (b) promote volunteerism and philanthropy in youth, and (c) make grant recommendations rooted in youth needs and determined priorities (Mawby, 1991).

\section{Growth of a Statewide Network}

Since the first YACs in Michigan began in the late 1980s, over 80 YACs have been formed to represent youth participation in almost every community foundation in the state. Although each YAC is structured slightly differently, the majority engages 15-20 diverse young people of high school age from the local community. Emphasis is placed on recruiting a group of young people that reflects the diversity of the community rather than a sole focus on traditional youth leaders. The goal of diversity is to ensure that the group includes a broad set of perspectives from the community. The communitybased YACs meet regularly to engage in grant making, service, and leadership activities.

The Michigan Community Foundation Youth Grant Making Project (MCFYP) was developed within the Council of Michigan Foundations to support the emergence of YACs within community foundations. MCFYP 
developed a committee of youth grant makers, supported by a Council of Michigan Foundations CMF staff person, who was charged with building capacity of youth grant makers in related activities and the capacity of adult advisors to work with young people. In addition, MCFYP provided an annual leadership conference and annual regional workshops to promote special topics and build capacity of youth grant makers on special issues including grant making, leadership, stewardship, and evaluation. This was done to build young people's capacity in advice giving and grant making.

Early in its development, CMF and MCFYP recognized the importance of adult advisors to the success of the YACs. Adults were essential to being able to support the youth grant makers, provide leadership training, and serve as a bridge linking the youth leaders with other adults in the community. Special training was developed to support adults in addition to creating a network for adult advisors to share ideas and lessons learned.

\section{Youth Grant Making in Action}

The Ann Arbor Area Community Foundation YAC, called the Youth Council, began in 1989 through the W. K. Kellogg Challenge Grant. Over the last 23 years, the Youth Council has created a space for young people to engage in grant-making efforts, strengthen the role of young people as leaders, and promote philanthropy and volunteerism in the community.

The Youth Council involves 20-25 young people of high school age, which aims to reflect the diversity of the Ann Arbor community. Members are recruited from across the community and generally represent the breadth of the various public and private high schools in the community to ensure all voices are represented on the councils. The process of selection is youth led. Interested youth complete an application and participate in a peer-interview process. Once selected, youth members are asked to stay on until they complete high school. In the last 22 years, there have only been a handful of young people that have left the Youth Council for reasons other than moving. In part this commitment reflects the strong engagement of the youth and the fact that they find the Youth Council a meaningful activity for them. When asked, many of the young people talk about the importance of their voice in grant-making decisions and their role as leaders in the community.

The Youth Council meets monthly. It is advised by a part-time staff member who provides overall guidance, feedback, and training, and serves as a liaison between the youth, the community foundation staff, and the Board of Trustees. A youth leadership team that includes cochairs, a secretary, a Board of Trustee member, and a Board of Trustee-in-Training leads the Youth Council. Youth Council members select their own leadership team through a nomination and vote process. The leadership team meets with the advisor regularly throughout the month to discuss process, set meeting agendas, develop leadership and training needs, and organize Youth Council activities. 
The inclusion of a Youth Council Trustee, a full voting member of the Board, was a testament to the importance of youth voice by the Foundation. The development of a Youth Trustee position was linked to the 1999 passage of a state "Youth on Boards Bill" that lowered the age in which people could serve as voting members of boards of directors from 18 to 16 years of age. The Council of Michigan strongly advocated for the legislation crafted in collaboration with youth members of the MCFYP committee. The Ann Arbor Area Community Foundation's first Youth Council Trustee member began her term in 1999. In every year since then, a young person has been selected to serve on the Board and participate in all decisions and voting rights as any adult member.

After the first few years, the Community Foundation developed a Trustee-in-Training role to provide a year of training before the youth assumes her/his voting role. This was done as a result of an exit interview with the then Youth Trustee, who raised the idea of a "training year" for youth members that would help the new Trustee to understand the complexities of the Ann Arbor Area Community Foundation and, as an extra benefit, be another young person at largely adult meetings. The Trustee-inTraining is typically selected in her/his junior year and is expected to attend all Board functions and meetings but does not have a vote in Community Foundation operations. In the following year, the youth is elected to the Board of Trustees and assumes all rights and roles as any other adult Board Trustee. Over the years, the Community Foundation learned that having at least two young people serving on an adult board helps provide mutual support and helps encourage participation. The ability to have a year of training also supports the Youth Trustee to be prepared to engage in the real decision-making needs of the Board. Youth are assumed to be active, not token, members of the Board of Trustees.

The major responsibility of the Youth Council is to make recommendations on grants that have been requested from the Community Foundation's Youth Fund. This occurs twice per year. The grant requests that come to the Youth Fund are first reviewed by Community Foundation staff for fit and for appropriate documentation; then the majority of the review and selection process is done by the Youth Council. During the actual grant process, Youth Council members review proposals, conduct interviews, and make recommendations on proposals and budgets. Per the terms of the W. K. Kellogg grant, all recommendations go through the Board of Trustees, as is the case with all grant proposals.

In preparation for the grant process, the Youth Council conducts leadership and grant-making training for its members. Among the training activities include discussing issues and setting priorities, assessing grant proposals, and reading budgets. The members also conduct sample grantmaking review processes to practice and discuss critical issues.

Over the last 23 years, the Youth Council also has engaged in various activities to raise the voice of young people within the Community Foundation 
and the community. For example, the Youth Council has led community forums on youth topics and special grant initiatives based on youth priorities. And they created a forum on youth-adult partnerships in the community and coauthored a proposal to create a comprehensive youth advisory council for a neighboring community. They led a mapping of activities and related focus groups to understand what teens wanted in after-school hours. Their findings, in conjunction with a community-wide feasibility study, led to the development of a challenge grant to launch a teen center that, 13 years later, continues to thrive as an organizational hub for youth engagement efforts in the community. Over the years, the Youth Council's efforts have encouraged, funded, and provided technical assistance to other organizations interested in engaging young people in advisory roles. As a result of their efforts, young people are advisors to local nonprofits; create youth-led leadership committees within organizations; and serve on committees for various school, city, and country government bodies. In addition, the Youth Council regularly supports youth philanthropy activities by engaging in community service and community-wide efforts aimed at promoting volunteerism among youth.

\section{Infusing Evaluation Into Youth Grant-Making Efforts}

Evaluation has been an important component to the Youth Council and to the Community Foundation since its inception. Although there had always been a variety of evaluation mechanisms in place, during the early to mid2000s there was a strengthened focus of evaluation by the Youth Council. In part this focus came from discussion about the importance of fidelity and also from a push by the larger MCFYP statewide network to encourage evaluation within youth grant making.

When discussed by the Youth Council, the members talked about evaluation as important for the following reasons: (a) it was the responsibility of the Youth Council to evaluate itself, its programs, and community; (b) it was the right of young people to be part of asking questions and gathering information about their community; (c) it was important for creating a history and documentation for other young people; (d) it was essential to ascertain the impact that the Youth Council and its grant making was having on the community; and (e) it was important to use the information to inform efforts and create changes in the community.

Although the Youth Council already conducted evaluation through grantee reports, community assessments, and general evaluation at the end of each year, the group decided to create a more systematic approach to its evaluation. As noted above, the Youth Council felt evaluation was critical to helping them increase the credibility of their advice and recommendation. Evaluation was a vehicle for them to show how seriously they took this work and the importance of being careful and systematic in their responsiveness to community needs. 
To do so, the Council formed a standing committee of three to four members. The members of the committee were selected by the leadership team for their interest in evaluation and represented a small subset of the overall Council. In addition, the leadership team appointed one member of the committee to help move evaluation efforts forward. The evaluation committee met regularly, inside and outside of meetings, to develop plans. The committee focused on evaluation in three ways: conducting internal evaluation of the Youth Council, conducting external evaluation of the grantees and the community, and using the information gathered for improving processes and prioritizing issues for action.

The internal evaluation efforts focused on documenting and assessing the work of the Youth Council. The goal for the internal efforts was to create a record of the activities, make program adjustments, and think more critically about their own process. Examples of activities that were developed included conducting periodic surveys of Youth Council members on meeting quality, program activities desired, and training and recruitment activities; holding debriefings (what went well, not so well, and improvements for next time) after events to ensure that evaluative information was documented for future planning; and creating an annual scrapbook to document the year's work through photographs, minutes, program activity materials, and write-ups about events and lessons learned. The internal evaluation efforts were used to improve grant-making practices, to improve meeting quality, and to capture the efforts of the Youth Council for the next year. For example, after an evaluation of the Youth Council meetings suggested that there was not enough opportunity for discussion, the leadership team developed strategies to make meetings more participatory and created committees to support small-group discussions within meetings.

The external evaluation efforts focused on understanding the community and assessing the impact of the Youth Council on the community. Examples of external evaluation included revamping grantee evaluation reports, conducting interviews with grantees, and engaging in grant-making site visits to assess impact.

Another component of the external evaluation was assessing community needs and issues. This aspect of evaluation was a component of the initial W. K. Kellogg Foundation funds that required youth grant makers to evaluate their communities' issues and priorities every 3 years. Through the grant-making committee, the Youth Council strengthened their approach by gathering comprehensive survey and interview data to assess community issues. For example, in 1 year, the Youth Council developed a comprehensive needs assessment, which involved a traditional survey approach and a video documentary to explore issues raised in the survey, and provided a vehicle for communicating their findings. The group analyzed their survey findings and then brainstormed additional questions and areas for information gathering. The youth brainstormed about people (youth and adults) to be interviewed and then reached out to ask the people to participate. 
In total, 30 youth and adults were interviewed. The video clips were then analyzed for topics and themes. The Youth Council was able to include survey findings in the video to support and illuminate the interviewee quotes. The final video was shown in the community to generate discussion and used to inform its members and the broader foundation staff and Board of Trustees about youth issues in the community. Over the years, the Youth Council has used their assessment findings to develop communitywide forums on priority topics such as youth-parent communication, teen stress, and youth leadership. These forums served as another vehicle for the Youth Council to have a voice in advising and lifting up key issues and providing a platform for youth and adults to come together around youth needs in the community.

To prepare for evaluation activities, the youth committee attended workshops and trainings sponsored by the MCFYP on evaluation. This included network-wide training and statewide conference experiences and small intensive trainings focused on developing and strengthening evaluation plans. For example, after attending a MCFYP training, the youth developed an hour-long training on evaluation, which they conducted at the orientation retreat. The training included a focus on understanding the what and why of evaluation, steps in the process, asking questions, and practicing conducting site visits. During the training, the YAC members developed questions to be used as part of a site-visit protocol. Following the training, YAC members conducted site visits with the use of the protocol developed. The information gathered was reported back to the whole YAC at an upcoming meeting, and was used to inform the next grant cycle process.

The youth also drew on the resources of their advisors, who had evaluation experience, and on related information and best practices that they compiled from other youth councils. Some of the evaluation committee members also created simplified forms and training protocols and developed peer-led mini-workshops on interviews, site visits, and survey development. The Youth Council also drew on the experience of past alumni, now in college, for support with surveys and data analysis.

\section{Empowering the Voice of Youth in Grant Making and Advising Community Issues}

The Youth Council as an advisory group and the subset evaluation advisory committee have played critical roles in ensuring that youth voices have an opportunity to impact practices, create organizational changes, and raise important community issues.

In many ways, the evaluation committee provided a space to lift up the evaluation efforts and allow for the broader Youth Council to be in a better position to enable youth voices to be heard-both within and beyond the group-because it created systematic approaches for the Youth Council to 
gather information, analyze their findings, and present their ideas. Youth members and adults in the Foundation and the broader community were receptive to ideas and changes developed by the youth, in part because they had been realized through evaluation efforts. Youth members could back up their ideas with facts, numbers, and quotes as evidence of their advice and recommendations. Thus, within the group, the evaluation committee helped build on strengths and identify areas for changes leading to better youth meetings, increased grant-making training, and assessing Youth Council activities and future directions. In addition, the ability to document and assess its activities allowed the group to share their approaches and practices with other youth grant makers. As a result the Youth Council has presented its efforts in statewide and national forums.

The overall Youth Council, as an advisory group, has also been critical for helping the broader Community Foundation set direction, examine needs of young people, and learn lessons from the youth. The Youth Council has helped to ensure that youth are seen as leaders in the community through funding the development of teen advisory boards in area organizations and providing funding to organizations that involve young people in program development and evaluation. It helped create needed partnerships to strengthen youth participation in the region, including the development of an area-wide coalition to increase opportunities for youth philanthropy and civic innovation in a neighboring community. Last, the focus on evaluation, and its use, has allowed for opportunities to use and share their findings with the community and therefore highlight critical issues facing youth. Overall, the youth council has helped to pave the way in the community for the role of young people and the ways young people can advise and set direction on practices and possibilities.

\section{Implications and Best Practices}

Young people should participate in advisory boards and committees, and this is especially true within foundations. Young people can and should have a voice in evaluating critical issues facing youth, advising the direction of grant making to address those issues, and strengthening programming and activities for young people in the community. As this case study makes clear, they can provide good advice-advice that is taken seriously because it includes multiple perspectives and is based in evidence. Evaluation further supported the credibility of their recommendations and other advice giving because it was a critical role in this process. Young people should have an opportunity for assessing their own programs and structures, asking questions about the community, and developing information that can be used for action. Overall, youth participation promotes the accountability of youth philanthropy and the foundations of which they are part.

Youth participation of this type, however, requires special understanding about process and best practices, as it can vary in implementation. 
Often the literature assesses participation through the lens of "authentic participation" or "meaningful participation" (Hart, 1992). In these cases, participation is not measured by the quantity of young people or numbers of activities, but rather by the quality of the participation, the level of engagement, and the ability for young people to have an authentic role in the process (Checkoway et al., 2003).

As youth grant advisory boards and youth evaluation advisory groups emerge, it will be critical for efforts to understand a basic set of principles about youth participation. To that end, there are a number of best practice documents that detail critical components needed to support youth as grant makers and youth evaluation.

Over the last 20 years, the MCFYP Council developed a set of best practices around youth philanthropy (see www.youthgrantmakers.org for more information). Many of the best practices, culled from lessons learned from various YACs, provide guides for the general development, support, and sustainability of such councils. The website lists 14 best practices for Youth Advisory Councils, including the following:

1. Meets a minimum of seven times a year.

2. Has a minimum of 12 members ages $12-21$ who reflect the many forms of diversity found in the local youth community.

3. Has two trained YAC advisors provided by the community foundation who are knowledgeable and supportive of youth development and youth leadership.

4. Holds an annual orientation for all new members and encourages all members to participate in training opportunities that will strengthen their skills in philanthropy.

5. Assesses critical issues of area youth at least every 3 years.

6. Engages in a grant-making process that is responsive to the critical issues of area youth annually.

7. Evaluates the effectiveness of each grant annually.

8. Participates in a community youth project annually.

9. Engages in fund development activities to assist with the continual growth of the endowed youth fund and the community foundation annually.

10. Has at least one YAC member serving as a full voting member on the community foundation Board of Trustees.

11. Interacts with community foundation board, staff, and donors regularly on a formal and informal level.

12. Has activities highlighted in the community foundation's annual report, website, newsletters, public presentations, and other communication tools.

13. Conducts an annual self-assessment to reflect upon its strengths, challenges, use of best practices, and opportunities for improvement.

14. Participates in and attends the Youth Grant Makers Summer Leadership Conference, Fall Regional Trainings, and Advisor Roundtables. 
In addition, sparked by a 2007 Wingspread Conference on Youth Participation in Public Policy, a group of scholars and practitioners worked to develop a set of underlying principles and values for youth participation (Sedonean, O'Doherty, Richards-Schuster, Ordeloa, \& Jackson, n.d.). At the core of these concepts is valuing young people as advisors and leaders in the community, providing authentic opportunities for young people to engage and advise outcomes, the importance of ongoing opportunities for young people, the need for training and education to support this participation, and the requirement that adults and organizational leaders buy in to the participation of young people in this way, and also provide the support needed for young people to be successful.

These principles highlight the importance of ensuring that young people's advice has meaning and influence and is not tokenized or treated in a decorated way (Arnstein, 1969; Hart, 1992). This is not about solely "adding more chairs to table" (Nyden et al., 1997), but rather the ability to add chairs that also guarantee that the advice of young people will have influence and will affect the conversations, priorities, and decisions made (Checkoway, 1998; Checkoway \& Richards-Schuster, 2006).

Youth Advisory Councils provide an especially interesting approach to authentic youth participation and youth advice-making approaches because they are linked to endowed funds. Tying youth participation and advice giving to sustained funding structures through endowed funds ensures that young people have a role in ongoing ways. In addition, through evaluation processes that are tied to the endowed funds, including needs assessments and other internal and external evaluation activities, young people provide a credible body for giving advice and helping shape the priorities of grant making related to youth in the community. Adult buy-in has been essential to the process and was required for the initial funding of the endowments. Over time, as adults connected to foundations have seen the importance of young people's advice in the grant-making process, it has helped reinforce the value of young people in this role. The commitments to evaluation and the training and responsibility taken by the young people, in their role, further enhance their credibility and build trust for their ideas.

Although this case has focused largely on the role of young people in advisory committees within foundations, it highlights some of the basic guidelines for engaging young people in advisory and evaluation advisory groups and provides lessons in future efforts aimed at working with youth on adult-majority evaluation advisory committees and with youth on youth-majority evaluation advisory committees:

1. Young people provide critical perspectives on community. They can and should have a voice and their insight contributes to the overall development of community programs and planning. Critical to the acceptance of young people's participation is having key staff-Executive 
Directors, Board Chairs, and key adults—also articulating the importance of youth voice and involvement. Organizational buy-in is crucial to creating sustained opportunities for authentic, nontokenized participation of young people.

2. Adults are essential to the engagement of young people. Too often efforts to engage youth in advisory roles focus solely on the youth without attention to the role of adults in supporting young people. Youth need adults who can be allies to their efforts and can serve as bridge between youth and adults. Advisory boards that engage youth need to take stock of the adults and provide training and education capacity building to support adults who are in this role.

3. Young people, like adults, need adequate training and education for their role. Efforts to engage young people on boards or councils should pay attention to providing the appropriate background information and preparation required to be able to engage in discussions and decision making. This may include attending special workshops, hosting retreats, or providing ongoing opportunities for education.

4. Diversity is important to ensure a broad-based perspective and range of ideas. In majority adult groups, young people bring different insight to the table and help to provide a broader understanding of the needs and issues in the community. Similarly, in youth-led councils, diversity across social identities and interests is essential for the overall discussion and representation of ideas and perspectives. Special attention needs to be paid to facilitating discussion across differences and ensuring that different perspectives are encouraged rather than isolated. In the case of youth on adult majority boards, having at least two young people serve can reduce isolation and build support to encourage participation.

5. Efforts to engage young people should involve a commitment to systematic information gathering in both internal and external evaluation efforts. Youth involvement is important in at least two aspects. First, when young people engage in evaluation efforts, they provide a new perspective through which to view data about the organization and community. As a result, the questions they ask and the information they gather often lead to important insights that strengthen their own efforts and improve programs and policies that impact young people. When this happens, the process of evaluation also empowers young people to have a voice in their community. Second, youth participation in evaluation also lends credibility to their advice and recommendations. When young people can legitimate their ideas in evidence and use data to back up their claims, it helps build trust for the importance of their perspective in decision making, especially in majority-dominated adult boards (Checkoway \& Richards-Schuster, 2006). 


\section{Conclusion}

Young people should participate in advisory committees focused on grant making and evaluation. The efforts in Michigan show this as a promising strategy for youth and community engagement. The impact of their participation shapes grant-making process, organizational structures, and the voice of young people in community issues. Evaluation advisory subcommittees further enhance the voice of young people by enabling them to assess their own functioning, learn from their experiences, and survey the issues in the broader community. The potential of these types of advisory structures, however, is limited by how participation is conceptualized and structured. As evidenced by the case example, participation needs to be valued, engaged, structured, and supported. And, when young people can be supported and adults can serve as allies, youth voices can be empowered in ways that can lead to organizational and community changes.

\section{References}

Arnstein, S. (1969). A ladder of citizen participation. Journal of the American Institute of Planners, 35, 216-224.

Camino, L., \& Zeldin, S. (2002). From periphery to center: Pathways for youth civic engagement in the day-to-day life of communities. Applied Developmental Science, 6(4), 213-220.

Checkoway, B. (1998). Involving young people in neighborhood development. Children and Youth Services Review, 20(9/10), 765-795.

Checkoway, B., Allison, A., \& Montoya, C. (2005). Youth participation in public policy at the municipal level. Children and Youth Services Review, 27, 1149-1162.

Checkoway, B., \& Gutierrez, L. (2006). Youth participation and community change: An introduction. Journal of Community Practice, 14(1/2).

Checkoway, B., \& Richards-Schuster, K. (2002). Lifting new voices for socially just communities. Community Youth Development, 2(4), 32-37.

Checkoway, B., \& Richards-Schuster, K. (2006). Youth participation for educational reform in low-income communities of color. In P. Noguera, S. Ginwright, \& J. Cammarota (Eds.), Beyond resistance: Youth activism and community change: New democratic possibilities for policy and practice for America's youth. New York, NY: Routledge.

Checkoway, B., Richards-Schuster, K., Abdullah, S., Aragon, M., Facio, E., Figueroa, L., ... Welsh, M. (2003). Young people as competent citizens. Community Development Journal: An International Forum, 38(4), 298-309.

Endo, T. (2002). Youth engagement in community-driven school reform. Oakland, CA: Social Policy Research Associates.

Falk, K., \& Nissan, L. (2007). A vision for and brief history of youth philanthropy. American Fundraising Professionals, 1.

Finn, J. (2001). Text and turbulence: Representing adolescence as pathology in the human services. Childhood, 8(2), 167-191.

Finn, J., \& Checkoway, B. (1998). Young people as competent community builders: A challenge to social work. Social Work, 43(4), 335-345.

Hart, R. (1992). Children's participation from tokenism to citizenship. Florence, Italy: UNICEF International Child Development Centre.

Mawby, R. (1991). Why youth? Why community foundations? Keynote address delivered by Dr. Russell G. Mawby, Chairman of the W. K. Kellogg Foundation, June 21, 


\section{EVALUATION AdVISORY GROUPS}

1991. Michigan Youth Community Foundation Project Best Practices. Retrieved from www.youthgrantmakers.org

Noguera, P. (2003). City schools and the American dream: Reclaiming the promise of public education. New York, NY: Teachers College Press.

Nyden, P., Figert, A., Shibley, M., \& Burrows, D. (1997). Building community: Social science in action. Thousand Oaks, CA: Pine Forge Press.

Sedonean, M., O’Doherty, R., Richards-Schuster, K., Ordeloa, A., \& Jackson, J. (n.d.). Youth participation in public policy. Unpublished working paper.

Tice, K. (2004). Leadership, volunteerism and giving: A longitudinal study of youth grantmakers (1993-2003). Grand Haven, MI: Council of Michigan Foundations.

Youth Leadership Institute. (2001). Changing the face of giving: An assessment of youth philanthropy. San Francisco, CA: The James Irvine Foundation.

Zeldin, S., McDaniel, A., Topitzes, D., \& Calvert, M. (2001). Youth in decision-making: A study on the impacts of youth on adults and organizations. Washington, DC: Innovation Center for Community Youth Development.

KATIE RICHARDS-SCHUSTER is an assistant research scientist, Michigan Youth and Community Program, School of Social Work, University of Michigan. 